\title{
Simulasi co-combustion batubara dan biomassa tandan kosong kelapa sawit tertorefaksi (torrefied biomass)
}

\author{
Zaenal Arifin ${ }^{1 *}$, Amrul $^{2}$, Muhammad Irsyad ${ }^{3}$ \\ ${ }^{1}$ Prodi Magister Teknik Mesin, Fakultas Teknik, Universitas Lampung \\ 2,3Jurusan Teknik Mesin,Fakultas Teknik, Universitas Lampung \\ JI. Prof. Sumantri Brojonegoro No.1 Bandar Lampung 35145, Lampung, Indonesia \\ ${ }^{*}$ Corresponding author: zaenal.1215021078@students.unila.ac.id
}

\begin{abstract}
Coal is still widely used as the main fuel in the industry, especially the power generation industry (PLTU), cement plants and etc. Coal is a fossil fuel whose availability is thinning and its fires produce $\mathrm{CO}_{2}$ emissions that cause a rise in greenhouse gas $(\mathrm{GHG})$ concentricity. On the other biomass is an alternative energy source that is abundant, including empty bunches of oil palm (TKKS), but has poor combustion properties compared to coal when burned directly. The properties of biomass burning can be improved by certain treatment, one of which is through the process of torrefaction. Biomass torrefaction has a calorific value equivalent to sub-bituminous coal B, so it has the potential to be used as an alternative fuel for coal. The purpose of this study was to determine the maximum temperature that occurs in the burner. In this study co-combustion was conducted on simulation of ANSYS program with powder system (pulverized combustion) because this type in recent decades is widely used in industry. In this study conducted a simulation on ANSYS to determine the temperature on the burner and the concentration of emissions produced. The results showed that the simulation of co-combustion burner burner showed the maximum temperature reached $970^{\circ} \mathrm{C}$. The effect of burner and burner temperature in the form of swirl provides sufficient oxygen with more perfect combustion resulting in decreased concentration of $\mathrm{CO}_{2}$ emissions and low concentration of $\mathrm{N}_{2}$ due to higher nozzle temperature. High temperatures lower the concentration of $\mathrm{SO}_{2}$ in the burn chamber.
\end{abstract}

Keyword: Co-combustion, pulverized co-combustion simulation, TKKS torrefaction, burner.

\begin{abstract}
Abstrak
Batubara hingga saat ini masih banyak digunakan sebagai bahan bakar utama di industri, kususnya industri pembangkit listrik (PLTU), pabrik semen dan lain sebagainya. Batubara merupakan bahan bakar fosil yang ketersediannya semakin menipis dan pebakarannya menghasilkan emisi $\mathrm{CO}_{2}$ yang menyebabkan naiknya konsentarsi gas rumah kaca (GRK). Disisi lain biomassa adalah sumber energi alternatif yang jumlahnya melimpah, di antaranya adalah tandan kosong kelapa sawit (TKKS), namun memiliki sifat pembakaran yang buruk dibandingkan dengan batubara apabila dibakar secara langsung. Sifat-sifat pembakaran biomassa bisa diperbaiki dengan cara treatment tertentu, salah satunya adalah melalui proses torefaksi. Biomassa tertorefaksi mempunyai nilai kalor yang setara dengan batubara subbituminus B, sehingga berpotensi dijadikan sebagai bahan bakar alternatif pengganti batubara. Tujuan penelitian ini adalah untuk mengetahui temperatur maksimum yang terjadi pada burner. Dalam penelitian ini Co-combustion dilakukan pada simulasi program ANSYS dengan sistem serbuk (pulverized combustion) karena jenis ini dalam beberapa dekade terakhir banyak digunakan di industri. Pada penelitian ini melakukan simulasi pada ANSYS untuk menentukan temperatur pada burner dan konsentrasi emisi yang dihasilkan. Hasil menunjukan simulasi cocombustion burner burner menunjukan temperatur maksimum mencapai $970{ }^{\circ} \mathrm{C}$. Pengaruh temperatur burner dan burner yang berbentuk swirl memberikan oksigen yang cukup dengan
\end{abstract}


pembakaran lebih sempurna sehingga menurunan konsentrasi emisi $\mathrm{CO}_{2}$ dan rendahnya konsentrasi $\mathrm{N}_{2}$ dikarenakan dari nozzle yang temperaturnya lebih tinggi. Temperatur yang tinggi menurunkan konsentrasi $\mathrm{SO}_{2}$ pada ruang bakar.

Kata Kunci: Co-combustion, pulverized co-combustion simulation, TKKS tertorefaksi, burner.

\section{Pendahuluan}

Energi merupakan salah satu kebutuhan utama pada saat ini terutama pada sektor rumah tangga, transportasi dan industri yang semakin meluas. Kebutuhan energi saat ini masih didominasi dengan sumber daya energi fosil, baik minyak bumi, batu bara, maupun gas. Sebagai energi tak terbarukan jika digunakan terus menerus ketersediaan energi fosil suatu saat akan habis.

Batubara merupakan peran utama dalam pemasokan sumber energi terutama pada sektor industri. Pembangkit listrik berbahan bakar batubara masih menduduki $41 \%$ produksi listrik dan diperkirakan akan mencapai $44 \%$ pada tahun 2030 [1]. Penggunaan batubara sebagai sumber pembangkit energi memiliki permasalahan yaitu meningkatnya gas rumah kaca (GRK), terutama karbon dioksida $\left(\mathrm{CO}_{2}\right)$, yang secara langsung terkait dengan pemanasan global. Perlunya sumber energi alternative yang ramah lingkungan salah satunya energi biomasa. Biomassa memiliki karakteristik karbon netral yang ramah lingkungan, karena produk utama karbondioksida telah dibebaskan selama proses pembakaran sebab berasal dari fotosintesis tanaman [2].

Indonesia merupakan negara agraris, ketersediaan biomasa yang sangat melimpah sehingga berpotensi sangat besar dalam hal energi biomasa. Jika biomasa digunakan sebagai sumber energi, biomasa memiliki beberapa keunggulan diantaranya dapat diperbarui (renewable) maka tergolong energi yang berkesinambungan [3]. Permasalahan dalam pemanfaatan biomasa sebagai sumber energi pada ketersediaan biomasa yang tersebar luas. Sehingga perlu pengumpulan yang mengakibatkan menambahnya biaya operasional. Pabrik kelapa sawit merupakan sumber limbah biomasa yang potensial, karena limbah yang dihasilkan telah terkumpul. Pabrik kelapa sawit memiliki limbah seperti tandan kosong kelapa sawit yang selama ini belum dimanfaatkan secara maksimal. Di sisi lain Tandan Kosong Kelapa Sawit (TKKS) memiliki kandungan air yang sangat tinggi sekitar $60-65 \%$, mengandung potasium $(\mathrm{K})$ mencapai $2,4 \%$, selain itu juga diketahui mengandung klorin $(\mathrm{Cl})$. Efek korosi akan meningkat dengan meningkatnya kandungan $\mathrm{Cl}$, dan unsur potasium dapat berperan dalam pembentukan deposit pada superheater yang dapat mengganggu proses perpindahan panas di tungku bakar [4].

Sehingga dalam pemanfaatan biomasa perlu adanya pre-treatment untuk meningkatkan nilai kalor dan menurunkan kadar air, agar menghasilkan bahan bakar padat dengan karakteristik yang baik mendekati karakteristik batubaara dalam hal nilai kalor. Salah satu pre-treatment yang dapat menghasilkan bahan bakar padat berkalori tinggi adalah proses torefaksi. Proses torefaksi didefinisikan sebagai perlakuan thermal dalam kondisi ringan, yaitu suhu antara $200-300{ }^{\circ} \mathrm{C}$.

Berbagai hasil penelitian torefaksi lanjut terhadap campuran sampah kota menunjukkan nilai kalor yang tinggi setara dengan batubara sub-bituminus B, 5200$5800 \mathrm{kcal} / \mathrm{kg}$ [5]. Biomasa sampah kota yang dilakukan proses torefaksi pada temperatur $275{ }^{\circ} \mathrm{C}$ dan waktu tinggal 30 menit pada reaktor kontinu tipe tubular menunjukkan nilai kalor yang cukup tinggi yaitu $5425 \mathrm{kcal} / \mathrm{kg}$ [6]. Briket tandan kosong sawit (TKKS) sebesar 5914,81 kcal/gr.

Upaya untuk mengurangi penggunaan bahan bakar fosil dan mencegah peningkatan emisi gas rumah kaca (GRK), maka perlu pemanfaatan biomasa TKKS sebagai energi baru dan terbarukan untuk kelanjutan ekosistem lingkungan. Untuk itu, pembakaran bersama (co-combustion) 
melalui simulasi dengan bantuan software ANSYS antara campuran batubara dan torefaksi biomasa TKKS dapat menyelesaikan permasalahan di atas.

\section{Tinjauan Teoritis}

\section{Deskripsi singkat co-combustion}

Co-combustion adalah proses pembakaran dua jenis bahan bakar berbeda dalam proses pembakaran yang sama, seringkali dioperasikan dalam ketel pembangkit uap. Dalam pengertian sederhana, pembakaran co-combustion dari batubara dengan biomassa dapat dipandang sebagai bagian dari sistem yang melengkapi perangkat boiler berbahan bakar batubara [7]. Biomassa memiliki karakteristik karbon netral yang ramah lingkungan, karena produk utama karbon dioksida telah dibebaskan selama proses pembakaran sebab berasal dari fotosintesis tanaman [2]. Namun, dibandingkan dengan pembakaran batubara, kerugian dari pembakaran biomassa adalah nilai kalori yang rendah, sehingga merusak tungku dan mengakibatkan slagging [8]. Akan tetapi, biomassa sebagai pembakaran-improver jika dicampur dengan batubara untuk menurunkan suhu pembakaran dan meningkatkan daya bakar [9].

Selain itu, transisi ini terutama disebabkan oleh menipisnya bahan bakar fosil dan masalah lingkungan seperti emisi gas rumah kaca (GRK) dan pelepasan unsurunsur yang berpotensi beracun melalui gas buang selama pembakaran batu bara. Unsurunsur yang berpotensi beracun adalah elemen logam apa pun (As, $\mathrm{Ba}, \mathrm{Bi}, \mathrm{Cd}, \mathrm{Cr}$, $\mathrm{Cu}, \mathrm{Ga}, \mathrm{Ni}, \mathrm{Pb}, \mathrm{Sb}, \mathrm{Sn}, \mathrm{Zn}$, dll.) memiliki potensi untuk menyebabkan bahaya kesehatan yang parah jika hadir dalam konsentrasi yang berlebihan. Apalagi emisinya di lingkungan adalah masalah perhatian utama saat ini [10].

Upaya untuk meningkatkan kualitas dari biomasa terus ditingkatkan, torefaksi merupakan salah satu metode yang bisa dilakukan. Proses dekomposisi termal terdiri dari tahapan yang berbeda tergantung pada suhu pembakaran. Tahap dehidrasi (25-135 $\left.{ }^{\circ} \mathrm{C}\right)$, tahap pelepasan komponen pembakaran dan volatil $\left(200-500{ }^{\circ} \mathrm{C}\right)$, tahap oksidasi dan kelelahan $\left(500-800{ }^{\circ} \mathrm{C}\right)$ [11].

Sung et al. [12] menemukan bahwa co-combustion jelas mengurangi pelepasan $\mathrm{SO}_{2}$ karena rendahnya kandungan $\mathrm{S}$ dan $\mathrm{N}$ di biomassa pada suhu tinggi. Hu et al. [13] mengungkapkan bahwa penurunan emisi SO selama co-combustion juga bisa disebabkan oleh efek penangkapan oleh logam alkali dan alkali tanah dari biomassa melalui reaksi sulfasi. Peng Wang, dkk., [14] melihat karakterisitik pembakaran $\mathrm{co}$ combustion menggunakan sampel cangkang inti sawit (PKS) sebagai biochar dan Yangquan batubara antrasit (YQ). Karakteristik pembakaran Bersama dan perilaku kinetik batubara bubuk dan campuran biochar diselidiki dengan analisis termogravimetri. Karakteristik fisik dan kimia YQ dan PKS dipelajari secara sistematis untuk mengeksplorasi perbedaan reaktivitas pembakaran antara YQ dan PKS. Dari beberapa penelitian co-combustion batubara dan biomassa TKKS tertorefaksi belum ada yang menggunakan dan memberikan informasi mengenai emisi yang ditimbulkan. Adapun yang memberikan informasi mengenai emisi co-combustion biomasa yang digunakan bukan menggunakan TKKS tertorefaksi, seperti yang dilakukan Zeyu dkk [15], biomasa yang digunakan adalah jerami gandum.

\section{Metode Penelitian}

A. Pemodelan

Metode co-combustion yang akan dilakukan dengan konsep NOx resduction Burner dimana pengurangan NOx berpengaruh pada reaksi reduksi dalam api. Penerapan ini menggunakan Swirl NOx tipe HT-NR3 yang saat ini banyak diterapkan pada boiler berbahan bakar batubara. Pembakaran Swirl NOx tunggal telah dilakukan oleh Zhou, dkk. [16] untuk mengevaluasi pembakaran batubara dan mengurangi kinerja emisi NOx yang dihasilkan.

Penelitian yang akan dilakukan dengan mengkombinasi biomassa TKKS 
tertorefaksi sebagai bahan bakar tambahan. Pemodelan yang dilakukan memiliki geometri yang lebih kecil dengan diameter dalam pipa $20 \mathrm{~cm}$ dan panjang $60 \mathrm{~cm}$ yang dapat dilihat pada Gambar 1. Pemodelan geometri mengunakan inventor 2019 dan pada simulasi pembakaran co-combustion menggunakan software ANSYS berlisensi dengan penentuan jumlah grind dan node meshing yang dapat dilihat pada Gambar 2 . Perhitungan iterasi menggunakan FLUENT. Simulasi menggunakan dimensi 2D dengan perpotongan di tengah kolom. Parameter yang diterapkan seperti kondisi batas, kondisi batas (boundary condition) pada simulasi digunakan untuk mendefinisikan bagian-bagian dari geometri pemodelan untuk pembacaan saat render di fluent.

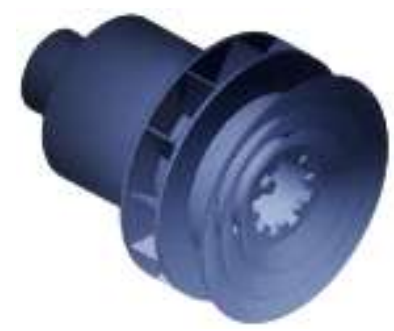

(a)

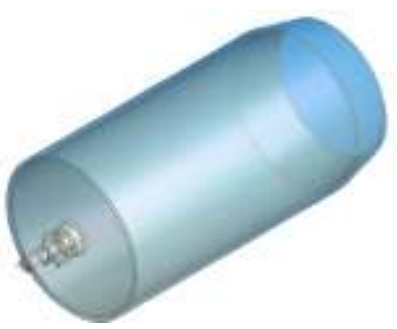

(b)

Gambar 1. Sekematik combustor chamber (a) Burner Nozzle; (b) combustor Burner

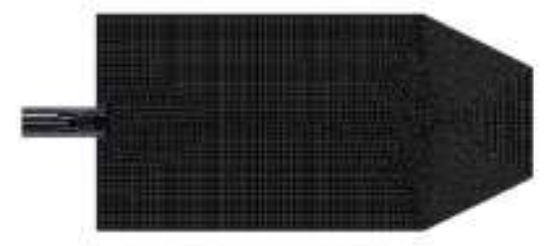

Gambar 2. Mesh ruang bakar

Pada simulasi diperlukan kondisi batas (boundary condition) dengan tujuan untuk mendefinisikan bagian-bagian dari geometri model untuk pembacaan pada saat running di fluent. Kondisi batas pada simulasi ini dapat dilihat pada Tabel 1.

Tabel 1. Kondisi batas

\begin{tabular}{cccc}
\hline Parameter & Inlet & Outlet & Wall \\
\hline Velocity $[\mathrm{m} / \mathrm{s}]$ & 15.24 & - & - \\
\hline $\begin{array}{c}\text { Mass flow rate of } \\
\text { COAL }[\mathrm{kg} / \mathrm{s}]\end{array}$ & 0.15 & - & - \\
\hline $\begin{array}{c}\text { Mass flow rate of TKKS } \\
{[\mathrm{kg} / \mathrm{s}]}\end{array}$ & 0.155 & - & - \\
\hline \begin{tabular}{c} 
Temperatur $\left[{ }^{\circ} \mathrm{C}\right]$ \\
\hline
\end{tabular} & 800 & - & - \\
\hline
\end{tabular}

B. Pembuatan unit co-combustion

1. Pengukuran Data Putaran (RPM) Motor Listrik

Tabel 2. Pengukuran data putaran (rpm) motor listrik

\begin{tabular}{cccc}
\hline No & Mesh & Frekuensi inverter & rpm \\
\hline 1 & 200 & 15 & 250 \\
2 & 200 & 30 & 332 \\
3 & 200 & 40 & 372 \\
\hline
\end{tabular}

2. Perhitungan Screw Feeder

a. Perhitungan secara teoritik

$$
\mathrm{Q}=\frac{60 \cdot \pi \cdot D^{2} \cdot \mathrm{S} \cdot \mathrm{n} \cdot \psi \cdot \rho \cdot \mathrm{C}}{4}
$$

b. Perhitungan secara aktual

Pengukuran laju massa batubara dihitung dengan alat bantu berupa stopwatch dan timbangan. Langkah pertama memasukkan batubara ke dalam hopper, setelah itu mengatur frekuensi kecepatan putaran motor yang diinginkan $(15,20$, dan $25 \mathrm{~Hz})$ pada inverter, kemudian menampung batubara ke dalam timbangan bersamaan dengan turunnya batubara dari screw feeder dan mencatat waktu yang dibutuhkan untuk $1 \mathrm{~kg}$ sampel yang tertampung. Pengulangan dilakukan sebanyak 3 kali setiap frekuensi.

3. Kebutuhan laju udara batubara subbituminus

Batubara sub-bituminus mengandung $58.8 \% \mathrm{C}, 1,3 \% \mathrm{~N}_{2}, 0,7 \% \mathrm{O}_{2}$ dan $0,7 \% \mathrm{~S}$. Berdasarkan hasil pengukuran dan perhitungan kandungan karbon, sulfur, nitrogen, hidrogen, oksigen dalam batubara antracite maka kebutuhan udara dapat dihitung sebagai berikut: 
Reaksi pembakaran carbon dengan oksigen adalah:

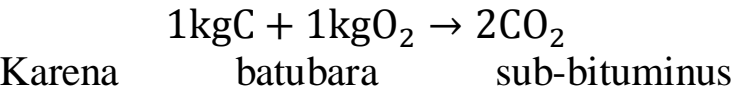
mengandung $58.8 \% \mathrm{C}$ maka persamaan reaksi di atas menjadi:

$$
58.8\left(1 \mathrm{kgC}+1 \mathrm{kgO}_{2} \rightarrow 2 \mathrm{CO}_{2}\right)
$$

Reaksi pembakaran hidrogen dengan oksigen adalah

$$
1 \mathrm{kgH}_{2}+1 \mathrm{~kg} \frac{1}{2} \mathrm{O}_{2} \rightarrow 2 \mathrm{H}_{2} \mathrm{O}
$$

Kandungan hidrogen dalam batubara subbituminus adalah $3,8 \%$, maka persamaan reaksi menjadi:

$$
3,8\left(1 \mathrm{kgH}_{2}+\frac{1}{2} \mathrm{kgO}_{2} \rightarrow 2 \mathrm{H}_{2} \mathrm{O}\right)
$$

Reaksi pembakaran antara sulfur dengan oksigen adalah:

$$
0.3\left(1 \mathrm{kgS}+1 \mathrm{kgO} \mathrm{O}_{2} \rightarrow \mathrm{SO}_{2}\right)
$$

4. Pengukuran laju massa udara pembakaran (m udara)

Pengukuran laju udara yang berasal dari air blower dapat diketahui dengan menggunakan persamaan dengan nilai $\mathrm{Vb}$ didapat dari hasil pengukuran kecepatan udara menggunakan alat ukur Anemometer.

C. Pekerjaan eksperimetal

1. Alat dan prosedur percobaan

Percobaan dilakuakan dengan metode pulverized co-combustion burner skala laboratorium. Sistem pengumpanan menggunakan screw conveyor yang di umpankan ke blower untuk di tembakan keruang pembakaran.

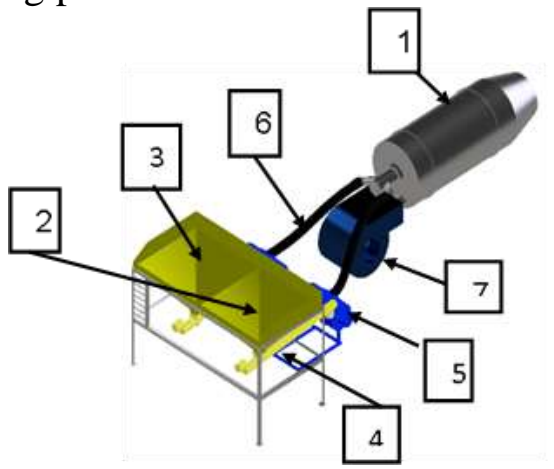

Gambar 3. Sekema unit co-combustion dalam penelitian ini. (1) burner (2) hopper biomassa (3) hopper batubara (4) screw conveyor (5) blower (6) selang (7) blower (secondary air).

Hasil dan Pembahasan
Co-combustion atau pembakaran bersama merupakan salah satu pilihan yang potensial untuk memanfaatkan limbah biomassa dan mengurangi penggunaan energi fosil. Co-combustion adalah salah satu pilihan yang berpotensi untuk meningkatkan reaktivasi oksidasi logam pada bahan bakar padat. Karena batubara memiliki kandungan karbon tetap yang lebih tinggi dibandingkan dengan biomassa yang mengakibatkan tidak dapat secara efektif terjadinya reaksi kimia oksidasi logam. Selain itu, dengan pembakaran bersama batubara dan biomassa, akan meningkatkan flash point sehingga mengurangi energi aktivasi yang dibutuhkan untuk reaksi pembakaran [17].

Guo dan Zhong [18] melakukan percobaan pembakaran bersama dan membuktikan bahwa biomassa dapat meningkatkan properti pengapian dan mempromosikan reaksi pembakaran batubara. Co-combustion dilaporkan secara signifikan mengurangi pelepasan baik $\mathrm{NO}_{\mathrm{X}}$ maupun $\mathrm{SO}_{\mathrm{X}}$ di pembangkit pulverized batubara yang sudah ada. Sung et al. [12] menemukan bahwa Co-combustion jelas mengurangi pelepasan $\mathrm{SO}_{2}$ karena rendahnya kandungan $\mathrm{S}$ dan $\mathrm{N}$ di biomassa pada suhu tinggi. $\mathrm{Hu}$ et al. [19] mengungkapkan bahwa penurunan Emisi $\mathrm{SO}_{2}$ selama co-combustion juga bisa disebabkan efek terikatnya emisi $\mathrm{SO}_{2}$ oleh logam alkali dan alkali tanah dari biomassa melalui reaksi sulfasi.

Dari beberapa referensi yang telah dilakukan belum adanya informasi mengenai co-combustion batubara dan biomassa TKKS tertorefaksi. Sehingga dilakukan penelitian co-combustion batubara dan biomassa TKKS tertorefaksi, dengan melihat emisi yang ditimbulkan dari kedua pembakaran bersama material tersebut. Dengan menggunakan bantuan software Autodesk Inventor dan Ansys sehingga dapat mempermudah melihat datadata yang diperlukan. Simulasi menggunakan dimensi 2D dengan perpotongan di tengah kolom.

Gambar 4 merupakan gambar 
distribusi temperatur pada simulasi yang dilakukan. Kontur berwarna merah menunjukkan tingkat temperatur paling panas pada burner. Terjadinya distribusi paling panas mendekati ujung burner karena disebabkan bentuk burner yang mengerucut dan pada ujung nozzle, serta bagian tengah lebih rendah karena sistem dari nozzle yang berbentuk swirl. Temperatur maksimum dari burner mencapai $970,758{ }^{\circ} \mathrm{C}$. Hal ini memungkinkan untuk melakukan eksperimen dengan temperatur burner sampai $1000^{\circ} \mathrm{C}$ sesuai dengan desain eksperimen.

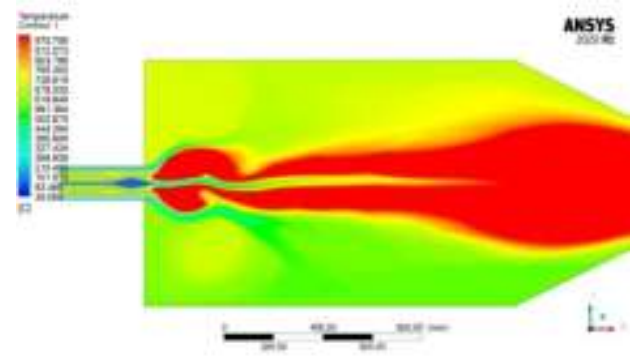

Gambar 4. Distribusi temperatur

Laju aliran dapat dilihat pada Gambar 5. Gambar tersebut merupakan bagian combustor yang memberikan informasi mengenai kontur dan distribusi radial kecepatan aksial gas buang di ruang bakar. Jika dilihat dari kontur warna menujukkan tekanan tertinggi pada Nozzel outlet. Untuk burner rendah NOx, zona resirkulasi pada tahap awal pembakaran batubara dan gas buang panas yang disirkulasi ulang dengan cepat dapat memanaskan partikel batubara dan TKKS. Hal ini berkontribusi pada daerah dinding dengan suhu gas tinggi dan konsentrasi oksigen rendah, yang membantu penyalaan cepat partikel batubara bubuk dan pengurangan pembakaran NOx.

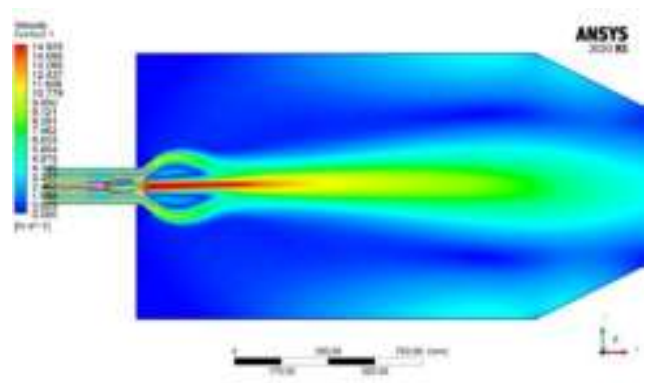

Gambar 5. Laju aliran Co-combution

Konsentrasi $\mathrm{CO}_{2}$ gas buang di ruang bakar ditunjukkan pada Gambar 6. Gambar tersebut mengilustrasikan konsentrasi $\mathrm{CO}_{2}$ di ruang bakar pada combustor. Jika dilihat pada gambar konsentrasi $\mathrm{CO}_{2}$ relatif terdistribusi secara merata sehingga akan memberikan efek pembakaran yang lebih sempurna. Selain itu konsentrasi terbentuk pada outlet nozzle dapat mempercepat terjadinya pembakaran sempurna di ruang bakar. Dari kontur Gambar 6 terlihat bahwa mass fraction $\mathrm{CO}_{2}$ paling besar ada pada kondisi outlet nozzle yang ditandai dengan warna kuning.

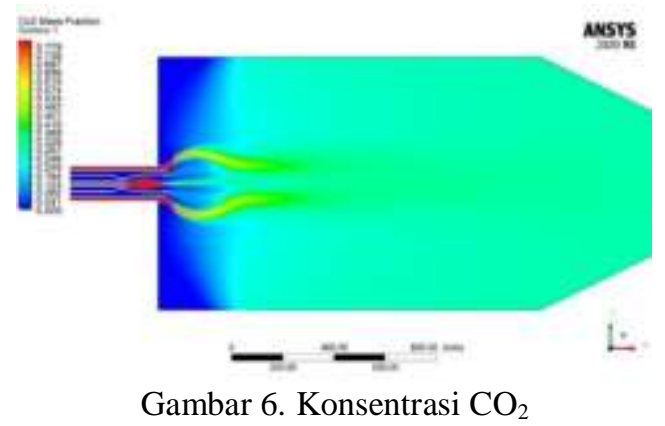

Konsentrasi $\mathrm{N}_{2}$ gas buang di ruang bakar dapat dilihat pada Gambar 7. Konsentrasi $\mathrm{N}_{2}$ tertinggi terbentuk pada outlet nozzle burner yang ditandai dengan warna orange kekuningan dan berwarna hijau seiring dengan menjauhnya dari outlet nozzle. Kontur warna hijau menujukkan rendahnya konsentrasi $\mathrm{N}_{2}$ hal ini dikarenakan menjauh dari nozzle yang temperaturnya lebih tinggi.

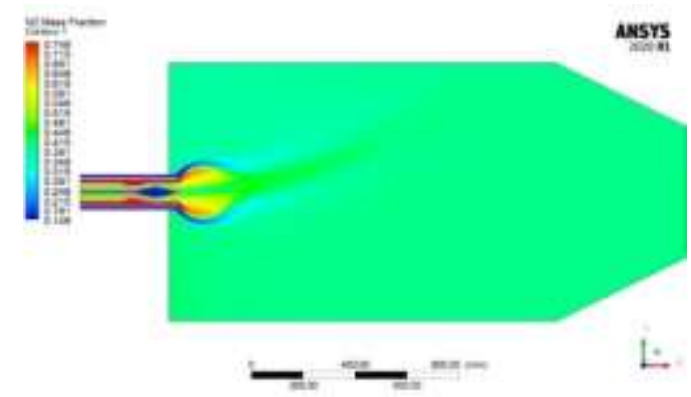

Gambar 7. Konsentrasi $\mathrm{NO}_{2}$

Konsentrasi sulfur dioksida $\left(\mathrm{SO}_{2}\right)$ gas buang di ruang bakar termasuk ke dalam kelompok sulfur oxide (SOx). Sebagian besar $\mathrm{SO}_{2}$ terbentuk dari hasil pembakaran bahan bakar fosil, terutama batubara. Gambar 8 mengilustrasikan kontur konsentrassi $\mathrm{SO}_{2}$ di ruang bakar atau 
combustor. Temperatur yang semakin tinggi akan menurunkan konsentrasi $\mathrm{SO}_{2}$ di ruang pembakaran.

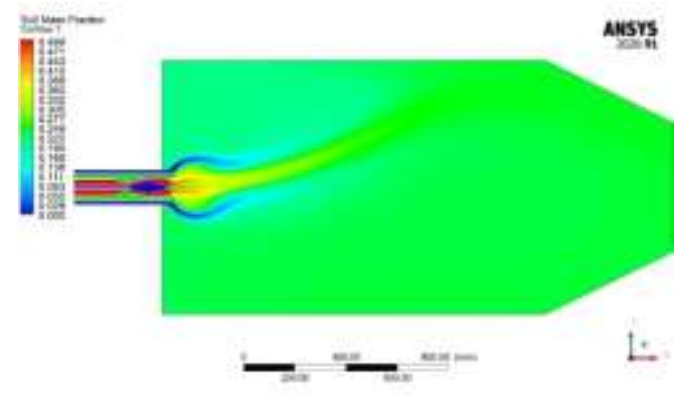

Gambar 8. Konsentrasi $\mathrm{SO}_{2}$

\section{Kesimpulan}

Berdasarkan hasil penelitian simulasi co-combustion burner dapat diambil kesimpuln bahwa hasil simulasi pada burner menunjukkan temperatur maksimum mencapai $970^{\circ} \mathrm{C}$ dengan distribusi temperatur paling tinggi di bagian unjung burner karena bentuk burner yang mengerucut. Pengaruh temperatur burner dan burner yang berbentuk swirl memberikan oksigen yang cukup dengan pembakaran lebih sempurna sehingga menurunan konsentrasi emisi $\mathrm{CO}_{2}$. Rendahnya konsentrasi $\mathrm{N}_{2}$ dikarenakan mejauh dari nozzle yang temperaturnya lebih tinggi. Temperatur yang tinggi menurunkan konsentrasi $\mathrm{SO}_{2}$ pada ruang bakar.

\section{Ucapan terimakasih}

Diucapkan terimaksih kepada bapak Amrul Hamzah beserta Muhammad Irsyad selaku pembimbing dan juga dari Kementerian RISTEK-DIKTI yang membiayai penelitian ini.

\section{Referensi}

[1] Mehmood, S., Reddy, B. V. and Rosen, M. A. (2012) 'Energy analysis of a biomass co-firing based pulverized coal power generation system', Sustainability, 4(4), pp. 462490. doi:10.3390/su4040462.

[2] Yildiz, Z., Uzun, H., Ceylan, S., Topcu, Y., 2016. Application of artificial neural networks to co- combustion of hazelnut husk-lignite coal blends. Bioresour. Technol. 200, 42-47.

[3] Hermawati, W., Mahmudi, Maulana, I., Rosaira, I. and Alamsyah, P. (2013) Sumber daya biomassa: Potensi enengi Indonesia yang terabaikan. Bogor: IPB Press.

[4] General Guide Biomass, 2010. The Asian Biomass handbook. The japan Institute of energy., 2010.

[5] Amrul, T. Hardianto, A. Suwono, A.D. Pasek, dan Adrian R.I,(2013): Konversi Bahan Bakar Padat dari Sampah Kota Melalui Torefaksi: Optimasi Temperatur Torefaksi komponennya, Proceedings Seminar Nasional Tahunan Teknik Mesin (SNTTM-XII), 2013, Bandar Lampung, 23-24 Oktober 2013, ISBN: 978-979-8510-61-8.

[6] Sanjaya, ika. 2018. Karakteristik Bahan Bakar Padat Produk Torefaksi Sampah Biomassa Campuran Pada Reaktor Kontinu Tipe Tubular. Bandar Lampung: Universitas Lampung.

[7] Wijayapala, W. D. A. S. and Mudunkotuwa, S. R. H. (2016). 'Cofiring of biomass with coal in pulverized coal fired boilers at Lakvijaya Power Plant: A case study', Engineer: Journal of the Institution of Engineers, Sri Lanka, 49(3), p. 33. doi: 10.4038/engineer.v49i3.7074.

[8] Mundike et al., 2018. Mundike, J., Collard F.X., Görgens, J.F., 2018. Cocombustion characteristics of coal with invasive alien plant chars prepared by torrefaction or slow pyrolysis. Fuel. 225, 62-70.

[9] Cong et al., 2019). Cong, K., Han, F., Zhang, Y., Li, Q., 2019. The investigation of co-combustion characteristics.

[10] Lynch D, Low F, Henihan AM, Garcia A, Kwapinski W, Zhang L, et al. Behavior of heavy metals during fluidized bed combustion of poultry 
litter. Energy Fuels 2014;28:5158-66. http://dx.doi.org/10.1021/ef500981k.

[11] He C, Wang K, Yang Y, Wang J. 2014. Utilization of sewage-sludgederived hydrochars toward efficient cocombustion with different-rank coals: effects of subcritical water conversion and blending scenarios. Energy Fuels 2014;28:6140-50.

[12] Sung, Y., Lee, S., Kim, C., Jun, D., Moon, C., Choi, G., Kim, D., 2016. Synergistic effect of co-firing woody biomass with coal on NOx reduction and burnout during airstaged combustion. Exp. Therm. Fluid Sci. $71,114 \mathrm{e} 125$.

[14] Peng Wang, Guangwei Wang, Jianliang Zhang, Jui-Yuan Lee, Yanjiang Li, Chuan Wang., 2018. Cocombustion characteristics and kinetic study of anthracite coal and palm kernel shell char.https://doi.org/10.1016/j.applthe rmaleng.2018.08.009.

[15] Zeyu Xue, Zhaoping Zhong, Xudong Lai., 2019. Investigation on gaseous pollutants emissions during cocombustion of coal and wheat straw in a fluidized bed combustor. https://doi.org/10.1016/j.chemosphere .2019 .124853

[16] Wijono, Agung, 2014. PLTU Biomasa Tandan Kosong Kelapa Sawit Studi Kelayakan dan Dampak Lingkungan. Balai Rekayasa Disain dan Sistem Teknologi - Badan Pengkajian dan Penerapan Teknologi Gedung 480, Kawasan PUSPIPTEK Serpong, Tangerang Selatan, 15314 Telp. 0217563213, E-mail: agung.wijono@gmail.com.

Simposium Nasional RAPI XIII - 2014 FT UMS.

[17] Zhou et al., 2016. Mechanism analysis on the pulverized coal combustion flame stability and NOx emission in a swirl burner with deep air staging. ttps://doi.org/10.1016/j.joei.2018.01.0 061743-9671/@ $2018 \quad$ Energy Institute.
[18] Guo dan Zhong, 2018. Influence of coal co-firing on the particulate matter formation during pulverized biomass combustion. https://doi.org/10.1016/j.joei.2018.05. 003.

[19] Hu, Z., Wang, X., Wang, Z., Wang, Y., Tan, H., 2014. Segmented kinetic investigation on condensed $\mathrm{KCl}$ sulfation in SO2/O2/H2O at 523e1023 $K$. Energy Fuels 28, $7560 \mathrm{e} 7568$. 